\title{
Paradoxical versus modulated conditional inferences: An explanation from the Stoicism
}

\section{Miguel López-Astorga}

\author{
Institute of Humanistic Studies "Juan Ignacio Molina" \\ University of Talca \\ milopez@utalca.cl
}

Received: 08.03.2016; Revised: 10.06.2016; Accepted: 10.06.2016

DOI: http://dx.doi.org/10.1590/0100-6045.2016.V39N1.MA

\begin{abstract}
According to standard propositional logic, the inferences in which the conditional introduction rule is used are absolutely correct. However, people do not always accept inferences of that kind. Orenes and Johnson-Laird carried out interesting experiments in this way and, based on the general framework of the mental models theory, explained clearly in which cases and under which circumstances such inferences are accepted and rejected. The goals of this paper are both to better understand some aspects of Stoic logic and to check whether or not that very logic can also offer an account on this issue. My conclusions are that, indeed, this later logic can do that, and that the results obtained by Orenes and Johnson-Laird can be explained based on the information that the sources provide on Stoic logic.
\end{abstract}

Keywords: conditional; inference; mental models; modulation; Stoicism

\section{Introduction}

Unfortunately, the information that today we have on Stoic logic is partial, limited, and fragmentary. Few theses of that logic are clearly known for sure, and what seems to be accepted without discussion is that it consisted of five á vaлó $\delta \varepsilon \imath \kappa \tau O \imath$ (i.e., five indemonstrables), and four $\theta \dot{\varepsilon} \mu a \tau a$ (i.e., four reduction rules). In addition, although it is true that interesting reconstruction efforts have been made (e.g., Bobzien, 1996), we keep descriptions of only two of the $\theta \dot{\varepsilon} \mu a \tau a$. 
This is, obviously, a problem because it makes it impossible to analyze all of the actual potentialities and possibilities of that logic. Thus, for example, it does not allow checking for certain whether or not the results of all of the different experiments that in recent times have been carried out in cognitive science are consistent with the basic theses of Stoic logic. However, I think that, despite these limitations, the information provided by the sources does enable to review the results of some of those experiments, and, in this paper, I will show this with regard to a study made by Orenes and Johnson-Laird (2012). That study addresses certain type of inferences that are called by the authors 'paradoxical.' Really, they do not refer to any paradox, and the authors use that word to indicate that, while the inferences are absolutely valid in Gentzen's (1935) natural deduction system, people tend to reject them. In particular, I will consider in this paper an inference related to the conditional introduction rule that is used by Orenes and Johnson-Laird (2012) in their experiments, and whose formal structure is this one:

$\neg \mathrm{B} / \operatorname{ergo} \mathrm{A}->\neg \mathrm{B}$

Where ' $\neg$ ' is negation and ' $->$ ' stands for the conditional.

This kind of inference is relevant because, as said, although we have little information on Stoic logic, the data that are kept allow interpreting and understanding the habitual responses that are given by participants involving it.

To argue in favor of this later idea is the main goal of this paper. To achieve it, firstly, I will describe in details the experimental conditions proposed by Orenes and Johnson-Laird (2012) in which inferences with the logical form indicated above are used. Secondly, I will comment on the explanation, based on the mental models theory (e.g., Johnson-Laird, 2004, 2006, 2010, 2012, 2015; Khemlani, Orenes, \& Johnson-Laird, 2014; Oakhill \& Garham, 1996; Orenes \& Johnson-Laird, 2012), of the results that they offer. Then, I will describe the theses of the Stoic logic that are needed to understand and interpret Orenes and Johnson-Laird's (2012) experiments. Finally, I will account for why Stoic logic is consistent with the results presented by Orenes and Johnson-Laird (2012) and how that logic can explain them. Of course, with this I do not try to prove that Stoic logic can be a better framework to understand human reasoning than the mental models theory, which is probably the current theory that can explain more 
results in reasoning tasks and in the simplest way. The point in this paper is only to check whether or not Stoic logic can explain certain particular experimental results, since, if that is so, it can help us better interpret the general approach of the Stoicism, which, as also stated, is not known in entirety.

\section{The experiments about the conditional introduction rule}

Orenes and Johnson-Laird (2012) propose different types of inferences in their experiments. In this way, the formal structure mentioned above is not the only one that they use. However, that is the structure that will be mainly reviewed in this paper and, for this reason, I will essentially focus on it. What is truly important about that inference is that it is undoubtedly valid and correct in standard logic, and that individuals sometimes consider it to be wrong.

Nevertheless, Orenes and Johnson-Laird (2012) identify the cases in which the inference is usually accepted and the cases in which it is habitually rejected. In their view, the argument is only accepted when "... a false if-clause implies a true then-clause..." (Orenes \& Johnson-Laird, 2012, p. 362; italics in text). Otherwise, it is rejected. Thus, according to them, a version of this paradox that individuals will not tend to accept is this one:

"Juan didn't buy a house. Does it follow that if Juan bought a car then he didn't buy a house?” (Orenes \& Johnson-Laird, 2012, p. 375).

In their opinion, people do not usually accept versions of the inference such as this one because, as said, a false antecedent does not lead to consider the consequent to be correct. Indeed, the fact that Juan does not buy a car does not involve that he does not buy a house. On the contrary, it is absolutely clear that to buy a car and a house are two different actions that are not related.

But they think that the situation changes when the requirement indicated is fulfilled. That is what happens, for example, in cases such as the one of this task:

"Pepe didn't buy a Mercedes. Does it follow that if Pepe bought a car then he didn’t buy a Mercedes?” (Orenes \& Johnson-Laird, 2012, p. 375). 
Now, an obvious relation between the antecedent and the consequent can be observed. If it is false that Pepe bought a car, it is also undoubtedly true that he did not buy a Mercedes, because a Mercedes is a car. So, it can be expected that individuals tend to accept versions of this later kind.

Orenes and Johnson-Laird (2012) call the inferences of the first type 'paradoxical inferences,' and those of the second type 'modulated inferences.' From now on, I will use those denominations too. In this way, it can be said that, in their paper, they include experiments in which it is demonstrated that their requirement works and is correct. People tend to accept modulated inferences to a greater extent than paradoxical inferences (for example, in their first experiment, while only $24 \%$ of participants accepted paradoxical versions, $60 \%$ of them accepted modulated versions; see Orenes \& Johnson-Laird, 2012, p. 366). In their view, the reason is evident and provided by the general theses of the mental models theory. I explain some of such theses, those that are relevant for this paper, in the next section.

\section{Analysis of possibilities and modulation in the mental models theory}

Overall, the mental models theory claims that reasoning consists of analyses of semantic possibilities named 'models.' In the inferential processes, people compare the different models corresponding to each sentence in the particular inference and reject those that, following the known data, are incompatible. However, what is interesting here is that the conditional propositions such as 'if $\mathrm{x}$ then $\mathrm{y}$ ' usually refer to three models:

$\mathrm{x}$

not-x

not-x y

y

not-y

Obviously, the first model describes a scenario in which both $\mathrm{x}$ and $\mathrm{y}$ are true, the second one a situation in which only $\mathrm{x}$ is false, and the third one a possibility in which both $\mathrm{x}$ and $\mathrm{y}$ are false. Actually, according to the theory, these are the 'Fully Explicit Models' of the conditional, and individuals do not always identify all of them. Nevertheless, what is important now is that, if this is so, the 
possibilities which the conditional included in the paradoxical version indicated above refers to are the following:

Juan buys a car

Juan does not buy a car

Juan does not buy a car
Juan does not buy a house

Juan does not buy a house

Juan buys a house

According to Orenes and Johnson-Laird (2012), the problem with this task is that the conditional is the conclusion, and that the premise provides that Juan does not buy a house. Therefore, the third model of the conditional (Juan does not buy a car \& Juan buys a house) is inconsistent with the premise, since in the model Juan does the opposite of what is stated in the premise, i.e., he buys a house. And, in their view, this is the main reason why people tend to reject the paradoxical versions of these arguments: the conclusions include a possibility that is incompatible with the datum established by the premise.

Nonetheless, the situation is different in the case of the modulated versions. The mental models theory also proposes that the human mind has certain mechanisms of modulation. The action of such mechanisms can lead to block certain models or semantic possibilities by virtue of the content, the meanings, or pragmatic factors. And this is exactly what occurs with the modulated versions that Orenes and Johnson-Laird include in their experiments. As said, the requirement is that the denial of the antecedent leads to the consequent, which causes that one of the three possibilities habitually corresponding to the conditional is blocked, in particular, the last one, i.e., the one that prevents that individuals accept the inference. This can be clearly seen if the mentioned example of modulated inference is considered. Indeed, the conditional embedded in that example only refers to two possibilities:

Pepe buys a car

Pepe does not buy a car
Pepe does not buy a Mercedes

Pepe does not buy a Mercedes

The third model (Pepe does not buy a car \& Pepe buys a Mercedes) is not possible now, since a Mercedes is a car and, if a Mercedes is bought, a car is bought. So, the controversial possibility is removed and this fact often leads individuals to admit this kind of inference as correct. 
As indicated, Orenes and Johnson-Laird (2012) carry out experiments whose results appear to prove that these theses of the mental models theory are right. And this means that this later theory can not only describe the mental processes implied in the arguments in which the conditional introduction rule is used, but also predict the results of such arguments.

But, as also mentioned, this paper is not intended to demonstrate otherwise. My only aim is to show that Stoic logic also has the necessary resources to explain, and even predict, this particular phenomenon. I do so in the next pages, but, previously, I start by explaining the main theses of Stoic logic that need to be taken into account to develop my arguments.

\section{Conditionals in Stoic logic}

As stated, the basic elements of Stoic logic are the five ávaró $\delta \varepsilon \imath k T o l$ (indemonstrables) and the four $\theta \dot{\varepsilon} \mu \alpha \tau \alpha$ (reduction rules). The indemonstrables are well known and described both in primary sources (e.g., Diogenes Laërtius, Vitae Philosophorum 7, 79-81) and secondary literature (e.g., Bobzien, 1996, p. 136; Boeri \& Salles, 2014, pp. 216-217; López-Astorga, 2015, pp. 3-12; O’Toole \& Jennings, 2004, p. 476). The most relevant aspect of them with regard to this paper is that only two of them, Modus Ponendo Ponens (A -> B, A / ergo B) and Modus Tollendo Tollens (A $->\mathrm{B}, \neg \mathrm{B} / \operatorname{ergo} \neg \mathrm{A}$ ), are directly linked to the conditional, and that none of them is akin or related to the conditional introduction rule.

As far as the reduction rules are concerned, as also indicated, although they were four, we only have information on two of them. The primary sources in this way are Galen, De Placitis Hippocratis et Platonis 114, 10; Pseudo-Apuleius, De Interpretatione 191, 5-10; Alexander of Aphrodisias, Aristotelis Analyticorum Priorum 278, 11-14; and Simplicius, In Aristotelis De Caelo Commentaria 273, 2-4. And, of course, there is also secondary literature addressing these passages (e.g., Bobzien, 1996, pp. 142ff; Boeri \& Salles, pp. 217ff).

However, the $\theta \dot{\varepsilon} \mu a \tau a$ are not interesting for this paper either. The key point is the criterion that the Stoics adopted to distinguish a correct conditional. Based on sources such as Sextus Empiricus, Pyrrhoniae Hypotyposes 2, 111; or Cicero, De Fato 12-16, most of the contemporary authors seem to agree about what that criterion was (e.g., Barnes, Bobzien, \& Mignucci, 2008, p. 107; Gould, 
1970, p. 76; López-Astorga, 2015, p. 9; Mueller, 1978, p. 20; O’Toole \& Jennings, 2004, p. 479). According to such authors, for the Stoics, or at least for Chrysippus

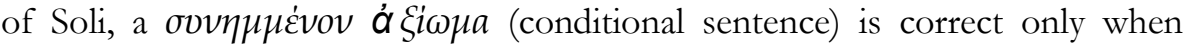

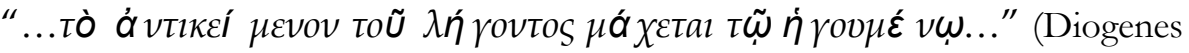
Laërtius, Vitae Philosophorum 7, 73), i.e., when 'the contrary of the then-clause

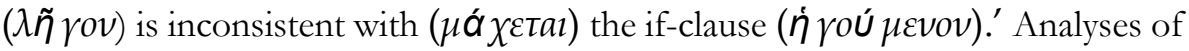
this particular passage are to be found, e.g., in López-Astorga $(2015$, p. 9$)$ and O'Toole and Jennings (2004, p. 492). Nevertheless, what is truly important for the aims of this paper is that this criterion of the conditional enables to understand and account for the results obtained by Orenes and Johnson-Laird (2012) in their experiments. The idea is that it is absolutely necessary that the ifclause and the then-clause are related in an evident way, to the extent that the antecedent is not possible without the consequent. Without such a relationship, it is not correct to consider the sentence to be a true conditional, and this point is essential to explain what happens in Orenes and Johnson-Laird's (2012) experiments.

A priori, the explanation of the results of the experimental conditions consisting of paradoxical inferences seems to be much simpler, since one might think that, to understand such results, it is not needed to pay attention to the Stoic criterion of the conditional. As mentioned, the inferences in which the conditional introduction rule has to be applied do not match any indemonstrable. Therefore, it can be thought that, from the Stoic point of view, it is clear why individuals tend to reject the conclusion, and that, in fact, that is the only result that can be expected. If the structure of the inference is not that of any indemonstrable, it absolutely makes sense that that inference is not admitted. Thus, if this is correct, the problem is only to account for why the modulated versions do be accepted. However, maybe the problem is more complex than it appears. For this reason, it can be opportune firstly to analyze what an inference such as that of the paradoxical example given above can actually mean in the general framework of Stoic logic.

\section{Paradoxical and modulated inferences from Stoic logic}

Actually, the fact that the inferences used by Orenes and Johnson-Laird are not indemonstrables alone is not a good explanation, since in Stoic logic 
arguments demonstrated from the indemonstrables can be accepted. Nevertheless, it appears that this is not the case of Orenes and Johnson-Laird's inferences either. On the other hand, Although it seems that not all of the Stoics agreed with the idea that arguments cannot have only one premise (Sextus Empiricus, Adversus Mathematicos 8, 443), it is practically certain that Chrysippus did not admit inferences of that kind. So, all of this can lead one to think that reasoning tasks such as those used by Orenes and Johnson-Laird cannot be interpreted as real arguments in general in Stoic logic (or, if preferred, in Chrysippus' logic).

But, given a speech akin to that of the paradoxical version described above, what can be thought from the Stoic perspective? An appropriate answer to this question can be that it is not being asked whether or not 'If Juan bought a car, then he didn't buy a house' can be logically inferred from 'Juan didn't buy a house,' but only whether or not 'If Juan bought a car, then he didn't buy a house' is a commentary that can be stated given the fact that Juan did not buy a house. In other words, the question is whether or not the meaning of the premise ('Juan didn't buy a house) semantically implies the conclusion ('If Juan bought a car, then he didn't buy a house).

In principle, it can be thought that what the conclusion really means is that, even in the hypothetical case that Juan has bought a car, he has not bought a house, which is clearly compatible with the premise. But the problem is that the word 'if' (which is the equivalent of the word $\varepsilon \dot{i}$ in Greek) appears in the conclusion, and, from the Stoic logic framework, that can lead one to think that it is intended to provide a relationship between the consequent and the antecedent such as the one that, according to Chrysippus of Soli, is necessary to consider the sentence to be a correct conditional. In this way, it can be interpreted that what is being asked is whether or not to buy a house (i.e., the opposite of the then-clause) is incompatible with to buy a car (i.e., the if-clause). The answer is obvious: to buy a house is not in conflict with to buy a car. Therefore, following Stoic logic, it is also obvious why individuals tend to reject arguments such as that of the paradoxical version described here. Its conclusion is presented as a conditional, but it does not fulfill Chrysippus' requirement. There is no link between the antecedent and the consequent, and the contrary of the consequent is not incompatible with the antecedent. So, the sentence is not a true conditional.

As far as the modulated version is concerned, it seems that, for these same reasons, it should be rejected as well (it is not an indemonstrable, it cannot be derived from one (or more) indemonstrable(s), it has only one premise, and 'if' is in 
the conclusion). However, it has an important difference from the paradoxical version. In this case, although the word 'if appears in the conclusion too, it is not possible to think that it is intended to provide a relationship between the two clauses similar to that claimed by Chrysippus. The reason of this is that, in this case, it is impossible that the opposite of the then-clause is inconsistent with the if-clause. In fact, the opposite of the then-clause is incompatible with the opposite of the if-clause, because, if a Mercedes is bought, evidently, a car is bought.

Therefore, faced to a conditional such as 'If Pepe bought a car, then he didn't buy a Mercedes,' although 'if' is used, individuals cannot think that it is a correct conditional, or that it is a sentence intended to be proposed as a correct conditional. According Chrysippus' criterion, it is not a conditional and it cannot ever be a conditional. And the cause is clear: it is absolutely obvious that the contrary of the then-clause implies the if-clause, and the former hence cannot be in any case inconsistent with the latter. Thus, given that the conclusion cannot be considered to be a conditional, the modulated version does enable to interpret that what that sentence means is that, even in the hypothetical case that Pepe has bought a car, that car is not a Mercedes, and, evidently, this can be accepted by the participants without difficulties. From this point of view, it is easy to understand why Orenes and Johnson-Laird's (2012) participants considered the versions akin to that modulated analyzed in this paper to be correct. Such versions do not derive a conditional from the premise. They only present as a conclusion a commentary that is obvious given the premise: in the case of our example, that Pepe could have bought a car, but, by virtue of the premise, it is absolutely sure that, if that was so, that car is not a Mercedes. And, as said, there is no chance of the conclusion being interpreted as a conditional sentence.

In this way, it can be supposed that, in Stoic logic, to fulfill Chrysippus' account was more important to conditionals than to include de word $\varepsilon \dot{\varepsilon}$ (if) in the sentence. But the most interesting point here is that, although, following the sources, the Stoics did not address cognitive phenomena similar to those of the paradoxical inferences related to the conditional introduction rule, their logic had (and has) the potential resources and machinery to account for inferences of that kind. 


\section{Conclusions}

A great problem is that, as mentioned, the sources only provide incomplete information on Stoic logic. Nevertheless, a productive task can be to try to rebuild it from the results coming from cognitive science today. Thus, the goal would be to detect or identify whether or not this ancient logic has the elements necessary to analyze or review those results. Of course, as said, that goal does not imply to review to what extend Stoic logic can be a theory describing human reasoning alternative to the mental models theory. Apart from the fact that several theories and logics, and not only Stoic logic and the mental models theory, can explain the particular problem addressed by Orenes and JohnsonLaird (2012), the literature shows that it is obvious that the mental models theory has a predictive power so strong that it is difficult to find a rival approach with a similar scope. In this way, the sense of this paper has been only, as mentioned, to come to a better understanding of certain aspects of Stoic logic.

That said, one might think that, in the particular case studied in this paper, i.e., the case of the Orenes and Johnson-Laird's (2012) inferences referring to the conditional introduction rule, Stoic logic has the necessary theoretical resources to understand the usual responses given by people. Therefore, it can be claimed that this later logic can explain why Orenes and Johnson-Laird (2012) obtained the results indicated in their paper with just its theoretical tools.

Maybe the key aspect is that held by Bobzien (1996, p. 134): Stoic logic is different from standard logic and both logics should not be compared. Based on this, I think that a very good way to work is to ignore standard logic and calculi such as that of Gentzen (1935), and consider Stoic logic alone in order to check whether or not it is able to explain certain cognitive problems that standard logic is not. As indicated, researches in this direction can be very useful to capture the true nature, sense, and characteristics of Stoic logic. And this is, exactly, what has been done in this paper by considering only a type of problematic reasoning exercise that is to be found in the cognitive science literature. As it is well known, there are many more exercises in that literature, and the results and arguments exposed in the previous pages show that, to the extent that this is possible, to address them from the perspective of Stoic logic can also be very relevant.

Furthermore, it can also be interesting to note that the explanation of the Stoics shares commonalities with that of the mental models theory. After all, based on the former, it can be stated that the conclusion of the modulated 
inference is accepted because the opposite of the then-clause is not inconsistent with the if-clause. What really happens is that, when the then-clause is false, the if-clause is necessarily true. On the other hand, as explained, according to the mental models theory, the inferences that are not rejected are those in which, when the if-clause is false, the then clause can only be true. Perhaps these are two ways to say the same: all of the sentences including the word 'if' (or $\varepsilon i$ ) are not always of the same type, since the truth-falsity relations existing between their clauses can cause them to be sentences of very different kinds.

\section{References}

Barnes, J.; Bobzien, S. \& Mignucci, M. Logic. In K. Algra, J. Barnes, J. Mansfeld, \& M. Schofield (Eds.), The Cambridge History of Hellenistic Philosophy (pp. 77-225). Cambridge, UK: Cambridge University Press, 2008.

BobZIEN, S. Stoic syllogistic. In C. C. W. Taylor (Ed.), Oxford Studies in Ancient Philosophy (pp. 133-192). Oxford, UK: Clarendon, 1996.

BOERI, M. D. \& SALLES, R. Los filósofos estoicos: Ontología, lógica, física y ética. Santiago de Chile, Chile: Ediciones Universidad Alberto Hurtado, 2014.

GENTZEN, G. Untersuchungen über das logische Schließen I. Mathematische Zeitschrift, 39, 176-210, 1935.

Gould, J. B. The Philosophy of Chrysippus. Albany, NY: State University of New York Press, 1970.

JOHNSON-LAIRD, P. N. The history of the mental models. In K. Manktelow \& M. C. Chung (Eds.), Psychology and Reasoning: Theoretical and Historical Perspectives (pp. 179-212). New York, NY: Psychology Press, 2004.

How We Reason. Oxford, UK: Oxford University Press, 2006.

Against logical form. Psychologica Belgica, 5(3/4), 193-221, 2010.

Inference with mental models. In K. J. Holyoak \& R. G. Morrison (Eds.), The Oxford Handbook of Thinking and Reasoning (pp. 134-145). New York, NY: Oxford University Press, 2012. 
How to improve thinking. In R. Wegerif, L. Li, \& J. C. Kaufman (Eds.), The Routledge International Handbook of Research on Teaching Thinking (pp. 8091). Abingdon, UK, \& New York, NY: Routledge, 2015.

Khemlani, S., ORenes, I., \& JOHnSOn-Laird, P. N. The negation of conjunctions, conditionals, and disjunctions. Acta Psychologica, 151, 1-7, 2014.

LÓPeZ-Astorga, M. Chrysippus' indemonstrables and mental logic. Croatian Journal of Philosophy, 15(43), 1-15, 2015.

Mueller, I. An introduction to Stoic logic. In J. M. Rist (Ed.), The Stoics (pp. 126). Berkeley, CA: University of California Press, 1978.

OAkHill, J. \& Garnham, A. (Eds.) Mental Models in Cognitive Science. Essays in Honour of Phil Johnson-Laird. Hove, UK: Psychology Press, 1996.

ORENES, I. \& JOHNSON-LAIRD, P. N. Logic, models, and paradoxical inferences. Mind \& Language, 27(4), 357-377, 2012.

O’Toole, R. R. \& Jennings, R. E. The Megarians and the Stoics. In M. D. Gabbay \& J. Woods (Eds.), Handbook of the History of Logic, Volume I. Greek, Indian and Arabic Logic (pp. 397-522). Amsterdam, The Netherlands: Elsevier, 2004. 